\title{
Clinical Primary Tumor TNM Finding
}

National Cancer Institute

\section{Source}

National Cancer Institute. Clinical Primary Tumor TNM Finding. NCI Thesaurus. Code C161009.

A clinical finding about one or more characteristics of a specific cancer, following the rules of the TNM classification system as they pertain to staging of the primary tumor. 